\title{
El uso de figuras retóricas en anuncios publicitarios y pinturas de Magritte: análisis sobre su efecto en la rememoración de marca en el corto plazo
}

\section{The use of rhetorical figures in advertising and Magritte's paintings: An analysis of its effect in short term brand recall}

\author{
LIZARDO VARGAS \\ Universidad de Piura, Facultad de Comunicación. Departamento de Comunicación. \\ lizardo.vargas@udep.pe \\ Marta Mensa \\ Universidad de Piura, Facultad de Humanidades. Departamento de Humanidades. \\ marta.mensa@udep.pe \\ ELIANA GonZALEZ \\ Universidad de Piura, Facultad de Humanidades. Departamento de Humanidades. \\ eliana.gonzalez@udep.pe
}

Recibido: 21 de diciembre de 2012

Aprobado: 27 de abril de 2013

\begin{abstract}
Resumen
El procesamiento de información y la memoria tienen una participación importante en la estimulación, codificación y rememoración de los estímulos publicitarios. El artículo procura identificar el impacto en la memoria de corto plazo de las figuras retóricas visuales mediante un estudio experimental comparativo entre anuncios publicitarios reales y en obras del artista Magritte intervenidas como anuncios. La hipótesis plantea que el uso de la figura retórica como parte del diseño de una pieza publicitaria debe tener un mayor efecto que en obras artísticas. Los resultados confirman la tesis y muestran que las piezas que utilizan la figura retórica con un elemento planificado logran un mayor índice de recordación en comparación con su uso en el arte magrittiano.
\end{abstract}

Palabras clave: figuras retóricas, memoria, publicidad, arte, Magritte.

Vargas, L., Mensa, M., Gonzales, E. (2013): El uso de figuras retóricas en anuncios publicitarios y pinturas de Magritte: análisis sobre su efecto en la rememoración de marca en el corto plazo. Arte, Individuo y Sociedad, 26 (1) 117-136 


\begin{abstract}
Information processing and memory have an important role in stimulating, encoding and recall of advertising stimuli. Through an experimental study the present article seeks to identify the impact on short-term memory of visual rhetorical figures, comparing real advertisements and works of artist Magritte intervened and presented as branded advertisements. The hypothesis states that rhetorical figures present in advertising designs should have a greater recall effects than artistic works. The results confirm the thesis, showing that the functional use of rhetorics as planned advertising elements achieve higher a recall rate compared to its use in Magritte's art.
\end{abstract}

Key words: rhetorical figures, memory, advertising, art, Magritte.

Vargas, L., Mensa, M., Gonzales, E. (2013): The use of rhetorical figures in advertising and Magritte's paintings: An analysis of its effect in short term brand recall. Arte, Individuo y Sociedad, 26 (1) 117-136

Sumario: 1. Introducción, 2. Revisión del corpus teórico, 3. Hipótesis, 4. Metodología, 5. Resultados, 6. Conclusiones, 7. Prospectivas y limitaciones. Referencias.

Este artículo recoge resultados de la investigación del uso de las figuras retóricas icónicas tanto en la publicidad como en el arte, y su impacto en la memoria del consumidor. La investigación ha sido financiada por la Facultad de Comunicación de la Universidad de Piura.

\title{
1. Introducción
}

Uno de los nombres más conocidos de la pintura surrealista belga es el de René Magritte (1898-1967). Su amplia y variada producción artística se inició en 1910 y se prolongó hasta el final de su vida (Torczyner, 1978; Paquet, 1994). A Magritte se lo conoce más como pintor que como publicista; sin embargo, cabe señalar que realizó anuncios publicitarios y hasta llegó a crear una agencia de publicidad. Como todo aprendiz, Magritte se introdujo en la pintura experimentando con los movimientos artísticos en boga: cubismo, modernismo, futurismo, dadaísmo y abstraccionismo (Passeron, 1980; Rodríguez, 2001). Pero a partir de 1925, Magritte deja de copiar para encontrar su propio estilo. Su filosofía se centrará en que el arte de pintar será el arte de pensar (Mensa y Roca, 2006). Su pintura se aproxima a la reflexión, el objetivo del artista consiste en cautivar y provocar al espectador a través de unas pincelas sutiles de ironía y humor (Schwilden, 1998). Magritte pretende encender e incentivar el pensamiento reflexivo y no el descriptivo del observador. Los cuadros de Magritte se convierten en imágenes de su pensamiento. Por ello, sus cuadros son de una simplicidad compleja (Mensa, 2009); es decir, el objeto es el protagonista del cuadro y todo elemento gratuito desaparece para resaltar el mensaje (Roca y Mensa, 2010). Nos encontramos, por lo tanto, delante de cuadros con imágenes simples y cotidianas pero con una idea compleja, donde éstas poseen las cualidades de lo insólito y lo improbable.

Lo que une a Magritte y la creatividad publicitaria son las figuras retóricas (Roque, 1983). Tanto Magritte como la publicidad usan este recurso para generar una sorpresa visual al espectador e insertar y consolidar un concepto dentro de la imagen (Cao, 1998). El arte y la publicidad siempre han ido de la mano. Si la consolidación del arte con la publicidad la estableció Toulouse Lautrec, elevando el cartel como obra de arte, se puede decir que Magritte utilizó sus cuadros como anuncios publicitarios. Es 
decir, el pintor belga descubrió que sus lienzos podrían vender productos; por ello, cuando tenía encargos publicitarios sólo seleccionaba uno de sus cuadros y colocaba el nombre de la marca. Esto fue posible porque Magritte se dio cuenta de que haciendo visible las figuras retóricas conseguía un efecto perturbador para así incentivar la comunicación con el consumidor (Roque, 1983).

El uso de figuras retóricas en la publicidad se hace cada vez más evidente. Estudios demuestran que con los años los publicistas recurren a la figura retórica para transmitir el mensaje de su anuncio porque así garantizan su recordación (Boozer, Wyld y Grant, 1991; McQuarrie y Mick, 1992 y 1993; Leigh, 1994). El creativo publicitario deja premeditadamente el mensaje de un anuncio abierto para que sea el consumidor el encargado de cerrarlo. Esta información faltante del anuncio sirve para generar sorpresa e incentivar la reflexión del consumidor. Magritte con sus cuadros hace exactamente lo mismo: "Magritte defamiliarizes the ordinary, causing us to speculate about how the mind supplies the missing information" (Levy, Levy y Goldberg, 2004, p. 86).

Respecto al funcionamiento de la publicidad, en los últimos cuatro decenios, distintos autores han tratado de explicar la forma en que ésta participa en la dinámica de la comercialización y el consumo de un producto o servicio. Uno de los artículos clásicos a este respecto fue el elaborado por Vakratsas y Ambler (1999).

Estos autores realizaron una exhaustiva revisión de la literatura científica sobre los estudios referidos al efecto de la publicidad en el consumidor. Su trabajo presenta un análisis taxonómico de los diversos modelos propuestos, donde los factores compartidos por varios modelos permiten establecer un esquema de funcionamiento común de la publicidad.

A lo largo de la revisión de la literatura realizada por Vakratsas y Ambler (1999) se observa que la experiencia y la memoria son variables que siempre se encuentran presentes en los modelos que explican el funcionamiento publicitario. Esto significa que dentro de la dinámica cognitiva de identificación y predisposición hacia una marca, la información almacenada en la memoria juega un papel importante, pues modula y manifiesta el grado de conciencia que la marca tiene en el individuo.

Más recientemente, la propuesta de un modelo sobre el funcionamiento de la publicidad y su efecto sobre la toma de decisión de compra ha sido presentada por Plassman, Zöega y Milosavljevic (2012). Los autores basan su esquema en variables como la identificación de la marca, el valor recordado y experimentado de la misma, así como el aprendizaje y reforzamiento de asociaciones con la marca. Estos elementos también presuponen una dinámica cognitiva por parte del sujeto donde la memoria de almacenamiento y la rememoración tienen un papel importante.

De esta forma puede afirmarse que en la comprensión del proceso publicitario, la memoria participa de modo relevante en la estimulación, aprendizaje y comprensión de las piezas publicitarias como estímulos.

Por otro lado es oportuno observar un contrapunto entre el papel social de la publicidad y la dimensión contemplativa-reflexiva de la obra de Magritte. Por una parte la publicidad manifiesta el objetivo funcional de promover la comercialización y consumo de marcas concretas. A pesar de que en esta prácica se utilicen elementos artísticos, la finalidad de los mismos no es el goce plástico: lo artístico en la publi- 
cidad se presenta como un recurso que tiene una función final comercial (Rodgers y Thorson, 2012; Vargas, 2003). Este hecho se advierte tanto las piezas individuales así como en todo el conjunto de anuncios que conforman la dinámica publicitaria de un mercado. De este modo la publicidad se presenta sea un importante partícipe y modelador de la denominada sociedad de consumo (Turow y Mcallister 2009; Purdun, 2009; Vargas, 2004).

Como se ha señalado, la obra magrittiana por su naturaleza artística tiene una finalidad contemplativa que se aproxima a la reflexión. Con el objeto de ir más allá de la descripción y procurar incentivar el pensamiento reflexivo en el espectador, las pinturas de Maggritte cargan las imágenes simples y cotidianas con ideas complejas. Mediante la manipulación de los objetos de sus obras éstos se presentan como insólitos e improbables. De ahí que Levy et al., (2004) sostengan que este artista hace especular acerca de cómo la mente suministra la información que falta en sus cuadros.

De esta manera es posible advertir una contraposición entre la naturaleza de la publicidad y la obra de arte, en este caso la de Magritte. Mientras la primera utiliza los recursos del arte con la función de captar la atención para fomentar el consumo de un bien comercializado, la segunda comparte la finalidad contemplativa de la obra plástica en concomitancia con un ánimo de suscitar en su espectador la reflexión y pensamiento crítico. Así nos encontramos ante dos realidades visuales que comparten elementos de composición pero difieren en cuanto a su finalidad, lo cual delimita la naturaleza de cada uno.

En este artículo se procura identificar el impacto de figuras retóricas visuales, utilizadas en piezas publicitarias gráficas, sobre la memoria y su posterior evocación por parte de los individuos. El uso de las llamadas figuras retóricas ha apuntado desde siempre a conseguir un fin estético concreto. Así, figuras como la metáfora, la hipérbole, hipálage, entre otras, han dado un salto desde el plano del lenguaje al plano de la imagen con el único objeto de llegar al espectador de una manera más atractiva. Por esta razón, las figuras retóricas como elemento de narrativa publicitaria se advierten tanto en anuncios reales como en las piezas de arte de Magritte. Intentaremos, mediante un estudio experimental, identificar el impacto en la memoria cuando se utiliza este recurso de composición visual en piezas publicitarias así como magrittianas.

\section{Revisión del corpus teórico}

Las investigaciones relacionadas con el arte y la publicidad son escasas. Una parte de los artículos se enfocan en el uso de la historia del arte en la publicidad. Hetsroni y Tukachinsky (2005) descubren que el arte renacentista es usado para promover productos caros y de prestigio. Este resultado coincide con el de Jiménez y Gómez (2006) que observan que los creativos publicitarios reutilizan las pinturas más famosas de la historia del arte para vender productos de lujo en revistas españolas femeninas.

Un segundo grupo de artículos se enfocan en las imágenes surrealistas en la publicidad. Homer y Kahle (1986) descubren que el uso de las imágenes surrealistas en la publicidad aumenta el interés del consumidor porque exigen que éste preste más atención al mensaje del anuncio. En este mismo plano Mostafa (2005) encuentra que 
el uso de técnicas surrealistas en la publicidad no implica elitismo para los consumidores egipcios, pero sí para los anglo-americanos.

Un tercer grupo de artículos se centra en los efectos de las propiedades artísticoestilistas de los anuncios en el consumidor (Hagtvedt y Patrick, 2008; Peracchio y Meyers-Levy, 2005, 1997 y 1994; Zhang, Yang y Peracchio, 2009). Hagtvedt y Patrick (2008) investigan el fenómeno del art infusion, en el que la presencia del arte visual (color, forma, composición, perspectiva, ángulo, etc.) tiene una influencia favorable sobre la evaluación de los productos de consumo. Estos investigadores muestran que las propiedades estilísticas y pictóricas del anuncio pueden comunicar conceptos que afectan a la percepción del producto por parte del consumidor. Peracchio y Meyers-Levy (2005, 1997 y 1994) y Zhang, et al. (2009) descubren que la actitud del consumidor puede variar dependiendo de cuáles sean sus propiedades estilísticas. Identifican que la atención del consumidor aumenta con algunas formas, con ángulos especiales de la fotografía y con el color.

Finalmente, otro grupo de artículos se enfoca en los patrones artísticos de la publicidad. Así, por ejemplo, Rossiter, Lagner y Ang (2003) proponen una exhaustiva tipología de ideas creativas visuales que las dividen en diferentes categorías. Según ellos, estas técnicas son herramientas útiles para los creativos para generar ideas. Por otro lado, Goldenberg, Mazursky y Solomon (1999) describen seis plantillas creativas que pueden ayudar en el proceso creativo a crear nuevas rutas para dar lugar a ideas más productivas. Mensa y Roca (2010) extraen patrones artísticos del arte magrittiano que se repite en la publicidad gráfica. Muchas de las técnicas, patrones o plantillas propuestos por los investigadores se basan en figures retóricas. Para Rossiter, Lagner y Ang (2003) la conexión entre las figuras retóricas, Magritte y la publicidad es el uso de imágenes poco usuales. Magritte descubrió que transformando una figura retórica en imagen consigue captar la atención del espectador, la publicidad hace exactamente lo mismo.

Los estudios sobre arte magrittiano y publicidad se reducen aún más. Mientras que la pintura de Magritte ha sido profundamente estudiada (Draguet, 2003; Lugrin, 2002; Foucault, 2001; Gablik, 2000; Ollinger-Zinque y Leen, 1998; Schwilden, 1998; Sylvester, 1997; Meuris, 1997; Paquet, 1994; Passeron, 1980; Torczyner, 1978), el Magritte publicista y la relación entre el arte magrittiano con la creatividad publicitaria actual es un área muy poco analizada. Roque (1983) publicó un ensayo sobre el arte de Magritte y la publicidad. Él es el primero en observar que los cuadros de los años 30 de este artista son figuras retóricas hechas visuales, y que esta técnica también se aplica en la publicidad. Roca y Mensa (2006) estudian los trabajos publicitarios de Magritte y descubren que el pintor belga se inició primero como publicista y después como artista. Mensa (2005 y 2009) realiza un planteamiento teórico comparando la evolución de la pintura de Magritte con los trabajos publicitarios que realizó Magritte desde 1926 hasta 1946.

Sobre las figuras retóricas en la publicidad, diversos estudios las analizan desde dos puntos de vista: las textuales (Calzada, 2011; Leigh, 1994; McQuarrie y Mick, 1993; Corbett, 1971; Phillips, y Mcquarrie, 2002; Hernández y Madrid, 1999; Sopory y Dillard, 2002; Mothersbaugh, Huhmann y Franke, 2002) y las visuales. En relación con las figuras retóricas visuales, se localizan artículos que tratan la persuasión; es 
decir, evalúan cómo las imágenes con figuras retóricas en anuncios gráficos inducen a alguien a creer en el mensaje (Jeong, 2008; Phillips, 2000; Boozer, 1991; Bathers, 1977).

Jeong (2008) compara anuncios con figuras retóricas con aquellos que no presentan ninguna. Como resultado encuentra que los anuncios con figuras retóricas son más persuasivos. También se relacionan las figuras retóricas con la percepción, es decir, cómo el espectador recibe esas imágenes a través de sus sentidos. Los estudios sugieren que la metáfora puede ser un buen mecanismo para aumentar la percepción del consumidor ante el anuncio porque las imágenes son más implícitas (Messaris, 1997; McQuarrie y Mick, 1999; Scott, 1994; Bulmer y Buchanan-Oliver, 2006; McQuarrie y Mick, 1996; Mick and Buhl, 1992).

En relación con los efectos de las figuras retóricas en el espectador existen dos posturas diferentes. Por un lado, los papers defienden que las figuras retóricas tienen un efecto positivo en el espectador ya que implica un esfuerzo intelectual, y por lo tanto, aumenta su interés y recordación (Jeong, 2008; Sopory y Dillard, 2002; Segler, 2001; Mio, 1996; Read et al., 1990; Bowers y Osborn, 1966; Reinsch, 1973; Greenwald y Leavitt, 1984; McQuarrie y Mick, 1992; Peracchio y Meyers-Levy, 1994; Mick, 1992). Según Segler (2001) "deeper analysis of a stimulus leads to a more persistent memory trace with depth referring to a greater degree of semantic involvement" (p. 23). Los resultados de la investigación de Jeong (2008) muestran que los anuncios con metáforas visuales son más persuasivos debido a la argumentación visual y a la retórica implícita del anuncio; mientras que los anuncios sin metáforas visuales disminuyen la capacidad cognitiva del espectador.

Para Sopory y Dillard (2002) las figuras retóricas captan la atención del consumidor por varias razones: cognitiva, ya que implica un pequeño esfuerzo intelectual; afectiva, ya que el consumidor tiene una actitud positiva ante el anuncio; motivacional, ya que el anuncio se convierte en un reto al tenerlo que descifrar y procesar, ya que aumenta la credibilidad del anuncio. Sin embargo, existe otro grupo de papers que advierte de los efectos negativos de las figuras retóricas visuales en la publicidad: cuando el consumidor no consigue descifrar el anuncio. Esta frustración puede provocar una actitud negativa ante el anuncio (Keyelaar y Van Gisbergen, 2006 y Van Mulken, Van Enschot y Hoeken, 2005; Meyers-Levy y Malaviya, 1999). Por ello, Phillips (2000) aconseja que un anuncio con una imagen de figura retórica debe ir acompañado de un texto que ayude a su comprensión, son los llamados anuncios verbo-pictorial figures. McQuarrie y Mick (1996) advierten que los mensajes que plantean escasas exigencias intelectuales fracasarán tanto como los que encierran demasiadas.

En cuanto a la literatura sobre la memoria, Surprenant y Neath (2009) señalan la ausencia actual de una teoría aceptada de forma mayoritaria en la academia sobre el funcionamiento y procesos de la memoria, aún a pesar de la gran cantidad de material reportado y publicado desde los últimos cincuenta años posteriores al devenir del interés y estudios en psicología cognitiva. Los autores indican que la memoria es un fenómeno en el que operan múltiples variables, y que además estas variables comprometidas en el funcionamiento de la memoria generan interacciones complejas 
que limitan el desarrollo de un modelo integrado de la memoria humana aplicable a la mayoría de los escenarios.

Atkinson y Shiffrin (1971) propusieron un modelo de funcionamiento donde la memoria operaba en forma secuencial y de compartimentos múltiples, el cual fue ampliamente aceptado. Sin embargo, este tenía la limitación de ser lineal y no contemplar el procesamiento simultáneo de información. Su diseño similar a un diagrama de flujo no describía la experiencia ordinaria en el uso de la memoria y la mente, ya que esta tiene la característica de atender varias tareas al mismo tiempo (Styles, 2005). De esta forma, la evidencia sugiere lo contrario, que una explicación de la memoria requiere mayor flexibilidad y explicación de su capacidad de combinar tareas (Ellenbogen y Meiran, 2008).

Posteriormente, Baddeley desarrolló el modelo denominado Memoria de Trabajo $(M T)$. Este se convirtió en una referencia importante para futuras investigaciones. La esencia del modelo de Baddeley es el 'Ejecutivo central', elemento que actúa como un controlador atencional. (Baddeley, 1986; Nairne, 2003; Eysenk y Keane, 2005). El 'Ejecutivo central' modera también otros componentes del modelo implicados en diversos grados de la codificación, procesamiento de información y la retención: el bucle fonológico, el bloc visuoespacial y el regulador episódico que sirve para almacenamiento en general (Eysenk y Keane, 2005).

El modelo $M T$ fue diseñado como una explicación más versátil de la memoria humana que el propuesto por sus antecesores Atkinson y Shiffrin. Por ello, el MT es más complejo y está elaborado sobre una estructura no unitaria compuesta por tres elementos distintos. Éstos, a su vez, están fraccionados y se subdividen en variables más pequeñas. De esta forma el $M T$ se convierte en un modelo adecuado para analizar los procesos simultáneos de la memoria de los sujetos.

En las últimas décadas, un amplio cuerpo de investigación ha apoyado este modelo, sobre todo debido a que $M T$ contempla el manejo en simultáneo de tareas complejas (ver Engle, Kane y Tuholsky, 1999). De esta manera, el modelo de Baddeley sigue vigente como uno de los más generalmente aceptados para observar y comprender la memoria.

Holyoak y Hummel (2001) sostienen que el aprendizaje ocurre cuando se crean nuevos enlaces entre la información procesada y almacenada en la memoria; es decir, cuando entra en funcionamiento la multiplicidad de factores que explican la dinámica de la memoria. De esta forma es plausible esperar que se originen nuevos enlaces cuando el individuo es expuesto a información nueva.

Ante una variación en la complejidad de esta nueva información que conforma los estímulos a los que el sujeto es expuesto, puede esperarse que se produzca una mayor elaboración mental, lo cual da pie a un mayor residuo en la memoria debido a la atención y elaboración realizada (Forceville, 1996; McQuarrie y Mick, 1999). Sin embargo, como se señaló en párrafos anteriores, un estímulo demasiado complejo puede reducir la comprensión del anuncio y causar incomodidad en el individuo (Keyelaar y Van Gisbergen, 2006), por lo que el resultante cognitivo asociado con figuras visuales complejas decae. De esta forma parece requisito la moderación en la complejidad visual de los estímulos para que estos sean oportunamente procesados y originen un rastro adecuado en la memoria. 
A su vez se ha advertido que el tiempo dedicado a mirar la publicidad aumenta el reconocimiento del estímulo, dado que una codificación más elaborada resulta en un mejor almacenamiento del mismo en la memoria. La distribución de esfuerzo cognitivo para procesar la información de las piezas publicitarias es proporcional con el esfuerzo mental que se requiere ante piezas retóricas visuales más complejas. De esta forma es una suposición razonable de que los individuos requieran más tiempo mirando la retórica visual, pues exige mayor elaboración cognitiva y el consecuente posterior impacto en la memoria (Lagerwerf, van Hooijdonk y Korenberg, 2012).

Por otro lado, se encuentra ampliamente reportado un efecto en la dinámica de exposición a estímulos y su evocación, denominado el efecto de primacía y recencia o curva de posición serial (Styles, 2005; Eysenk y Keane, 2005; Azizian y Polich, 2007). El principio es sencillo pero consistente: cuando a un grupo de individuos se le presenta una serie de elementos para que sean atendidos, al cabo de un breve lapso recuerdan con mayor facilidad aquellos ítems que se presentaron al principio (primacía) o los que se presentaron al final (recencia) de la serie, y con mayor dificultad aquellos elementos intermedios que también formal parte de la colección.

\section{Hipótesis}

El racional de esta investigación es que la publicidad utiliza figuras retóricas visuales o icónicas de modo funcional, con la finalidad de lograr mensajes que capten la atención y así facilitar que marcas sean recordadas por el consumidor. Por otro lado, las obras de arte de Magritte también utilizan figuras retóricas visuales, pero con una finalidad no funcional sino más bien contemplativa y reflexiva.

Este estudio procura identificar en cuál de ambos casos el uso de las figuras retóricas origina un mayor índice de recordación de las marcas anunciadas, sea mediante piezas originalmente publicitarias o de pinturas del artista belga conteniendo nombres de marcas. De esta manera, la hipótesis que se plantea es la siguiente:

H1: La publicidad utiliza las figuras retóricas para crear conciencia y recordación de marca, mientras las obras de arte magrittianas lo hacen con el objeto de originar una contemplación reflexiva artística. Con lo cual, el efecto sobre la memoria y rememoración de marca logrado por las figuras en la publicidad debe ser mayor que la recordación originada por las figuras presentes en las obras de Magritte.

Si bien las piezas publicitarias tienen un componente artístico, su finalidad contrasta con aquella de las obras de arte. Como se ha expuesto, éstas últimas utilizan una narrativa visual cuyo objeto es la contemplación. No por ello en ambos casos se deja de transmitir un mensaje. En congruencia con la literatura existente, para que la comunicación logre su cometido es conveniente que el mensaje sea procesado por el sujeto en un moderado o alto grado de involucramiento (Mitchell, 1981; Zaichkowsky, 1994; Andrews, Durvasula y Akhter, 1990; Vargas, 2005). El uso de las figuras retóricas requiere del individuo un esfuerzo cognitivo para comprenderlas y darles sentido, lo cual sucede en concomitancia con un alto grado de involucramiento, que a su vez facilita de que el mensaje sea almacenado en la memoria y posteriormente rememorado. 


\section{Metodología}

Para la metodología se diseñó un estudio cuasi experimental cuantitativo de testeo y retesteo entre grupos. La metodología se halló en concordancia con la hipótesis del estudio, orientada a determinar si las figuras retóricas utilizadas en las piezas originariamente publicitarias obtenían una mayor recordación que las figuras retóricas utilizadas en las obras de Magritte, estas últimas intervenidas como gráficas publicitarias. Se buscó una puntuación significativa en $p<.05$

Muestra. La población estudiada estuvo compuesta por una muestra no probabilística de $N=34$, estudiantes de una universidad en la ciudad de Lima, correspondientes a niveles socioeconómicos homogéneos (medio alto y alto). Los encuestados pertenecían a ambos sexos. Estos fueron seleccionados de forma aleatoria simple y debían cumplir con el requisito etario de tener entre 20 y 25 años. La muestra constó de dos grupos, uno de testeo (Grupo 1, $n=21$ ) y otro de retesteo (Grupo 2, $n=13$ ) (ver Tabla 1).

\begin{tabular}{lcccc} 
& Media & Mediana & Moda & DS \\
\hline Grupo 1 & 22,8 & 23 & 23 & 0,9 \\
\hline Grupo 2 & 22,6 & 22 & 21,8 & 1,1 \\
\hline
\end{tabular}

Tabla 1. Estadistica descriptiva etaria de los Grupos 1 y 2.

Variables. La variable independiente testeada fue la exposición de figuras retóricas icónicas (no textuales) en piezas gráficas publicitarias. Esta variable tuvo dos niveles: un inventario de piezas originariamente elaboradas por agencias de publicidad $(\mathrm{Pb})$ y otro inventario de piezas magrittianas $(\mathrm{PbM})$, a las cuales se les colocó un logotipo para presentarlas como anuncios publicitarios. En estos dos niveles las marcas utilizadas eran las mismas, con el objeto de permitir una comparación en el estudio.

La variable dependiente fue el índice de recordación espontánea de corto plazo por parte de los participantes de ambos grupos respecto a las marcas exhibidas en las piezas.

Procedimiento e instrumentos. Con el objeto de realizar el experimento se desarrollaron dos instrumentos.

Por una parte, una colección de diez piezas originalmente publicitarias $(P b)$ a las cuales se les eliminó digitalmente todo texto, dejando sólo los elementos gráficos de figuras retóricas y el logotipo de la marca. Por otro lado, una segunda colección de diez obras de arte de Magritte $(P b M)$ a las cuales se les insertó digitalmente el logotipo de una marca. En ambas colecciones las marcas se repetían en una pieza publicitaria y en una obra de Magritte, con independencia de su coincidencia en el uso de la figura retórica.

Al inicio y al final de las colecciones se introdujeron dos piezas publicitarias carentes de figuras retóricas y de marcas distintas a las utilizadas en $\mathrm{Pb}$ y en $\mathrm{PbM}$, con 
la finalidad de controlar el efecto de primacía y recencia. Se denomió a estas piezas como neutras $(P b S)$.

La metodología utilizada en el estudio de testeo y retesteo aplicada a ambos grupos de experimentación se ilustra en la siguiente figura (Fig. 1):

\begin{tabular}{lllll} 
Grupo 1 (testeo) & $\mathrm{PbS}$ & $\mathrm{Pb}$ & $\mathrm{PbM}$ & $\mathrm{PbS}$ \\
\hline Grupo 2 (retesteo) & $\mathrm{PbS}$ & $\mathrm{PbM}$ & $\mathrm{Pb}$ & $\mathrm{PbS}$
\end{tabular}

Figura 1. Esquema de la metodología de testeo y retesteo aplicada en el estudio.

Para la elaboración de ambas colecciones se seleccionaron marcas de distintas categorías de productos y servicios conocidas por los participantes de ambos grupos. Las marcas seleccionadas fueron: Vivanda (supermercados); Hi-Tec (zapatos de montaña); Sodimac (retail para suministros de construcción); Mentos (caramelos); Baronet (trajes para hombre); Armani (perfume para hombre); Rosatel (floristería); Ray-Ban (gafas de sol); Lan (aerolínea) y Dior (perfume para mujer). Las marcas carentes de figuras retóricas o neutras utilizadas para atender el efecto de primacía y recencia fueron Gloria (lácteos); Daihatsu (automóviles); Americatel (telefonía) y Sublime (chocolates).

Una vez seleccionados los 20 anuncios se identificaron sus figuras retóricas. En el caso de los anuncios de Magritte $(P b M)$ la información se obtuvo del ensayo de Roque (1983) y en el de los anuncios publicitarios $(P b)$ por los autores del artículo. Referirse a las tablas 2 y 3 para ver las figuras retóricas presentes en cada pieza $P b$ y $\mathrm{PbM}$, así como la cantidad de figuras en cada caso.

\begin{tabular}{lll} 
Marcas & $\mathrm{Pb}$ & $\mathrm{PbM}$ \\
\hline Vivanda & Metáfora & Hipérbole \\
\hline Hi-tec & Metáfora & Metáfora \\
\hline Sodimac & Hipérbole & Hipérbole \\
\hline Mentos & Metáfora & Hipérbole \\
\hline Baronet & Analogía & Hipérbole \\
\hline Armani & Analogía & Metáfora \\
\hline Rosatel & Analogía & Hipérbole \\
\hline Ray-ban & Comparación & Metáfora \\
\hline Lan & Hipálage & Hipálage \\
\hline Dior & Hipérbole & Metáfora \\
\hline
\end{tabular}

Tabla 2. Figuras retóricas de la marca según el anuncio publicitario o el magrittiano. 


\begin{tabular}{lccc} 
Figuras retóricas & $\mathrm{Pb}$ & $\mathrm{PbM}$ & Total \\
\hline Metáfora & 3 & 4 & 7 \\
\hline Hipérbole & 2 & 5 & 7 \\
\hline Analogía & 3 & 0 & 3 \\
\hline Comparación & 1 & 0 & 1 \\
\hline Hipálage & 1 & 1 & 2 \\
\hline Total & 10 & 10 & 20 \\
\hline
\end{tabular}

Tabla 3. Número de figuras retóricas en los anuncios publicitarios y los magrittianos.

Como variable de contrabalanceo al Grupo 1 se les exhibieron primero las piezas publicitarias seguidas de las piezas de Magritte. En al caso del Grupo 2 se invirtió el orden de exposición, donde primero fueron las piezas magrittianas y luego las publicitarias.

Antes de la experimentación se realizó una prueba piloto con un grupo de alumnos universitarios $(\mathrm{n}=18)$ con la finalidad de determinar los tiempos correctos de exposición de las piezas, la identificación y familiaridad con las marcas, el tiempo adecuado para la rememoración así como las instrucciones del experimento. Hubo que hacer un ajuste en el tiempo de exposición de las piezas con la finalidad de no causar tedio entre los participantes.

En su encuentro con cada grupo, el experimentador expuso como explicación de señuelo que participarían en un estudio sobre la relación entre el efecto del uso los colores en la publicidad y los logotipos en distintas marcas.

La experimentación se aplicó de forma colectiva a cada grupo, pidiendo que no interactuasen entre ellos durante el tiempo que durase la misma. Se realizó dentro de un aula de la universidad. Se le entregó una hoja en blanco a cada participante. Cada pieza de ambas colecciones fue exhibida durante 20 segundos.

Inmediatamente después de la exposición se les pidió a los sujetos que escribieran su edad y sexo en el papel entregado. A continuación les pidió que escribieran las marcas que recordaban haber visto. Para ellos se les dejó un lapso de 30 segundos. A continuación se les solicitó que al lado de cada marca recordada hicieran una breve descripción del anuncio donde evocaban haber visto la marca (con el objeto de determinar si se referían a una pieza $\mathrm{Pb}, \mathrm{PbM}$ o a una $\mathrm{PbS}$ ).

El investigador no ofrecía asistencia a los participantes. Posteriormente se recolectaban los papeles con las respuestas de los individuos. A continuación se hacía el debrief con ambos grupos, explicando el objeto real del estudio y -siguiendo los protocolos de ética en investigación- dejando abierta la posibilidad de que quien lo desease pudiera retirar su hoja de respuestas. 


\section{Resultados}

Los resultados fueron procesados en SPSS y la herramienta estadística utilizada fue la Distribución $t$ de Student, pues la investigación tenía por objeto observar la diferencia entre dos grupos en una variable de interés. En este caso, el índice de rememoración en el corto plazo de las marcas anunciadas utilizando figuras retóricas en piezas publicitarias o bien en piezas de arte.

El análisis aplicado para identificar las diferencias en función a la media de puntuaciones de recordación entre $P b$ y $P b M$ evidenció que los participantes del estudio evocaron de modo significativamente mayor las piezas diseñadas originariamente como publicidad $(\mathrm{Pb})$ en comparación con las piezas magrittianas intervenidas. La estadística entregó el siguiente resultado $t_{(18)}=.799, p<.435$, prueba bilateral. De esta manera se cumple la hipótesis alternativa $H 1$.

Cabe señalar que en los resultados se observó una similitud entre la media general de recordación las marcas utilizada en el estudio en las dos condiciones. En el caso de $P b$ esta fue de 9.2 y en el caso de $P b M$ fue de 7.9. Asimismo las desviaciones estándar entre ambas puntuaciones fue similar, 1.1 y 1.2 , respectivamente.

La figura con barras de error que compara la evocación entre las dos condiciones $\mathrm{Pb}$ y $\mathrm{PbM}$ muestra estos resultados (ver Fig. 2):

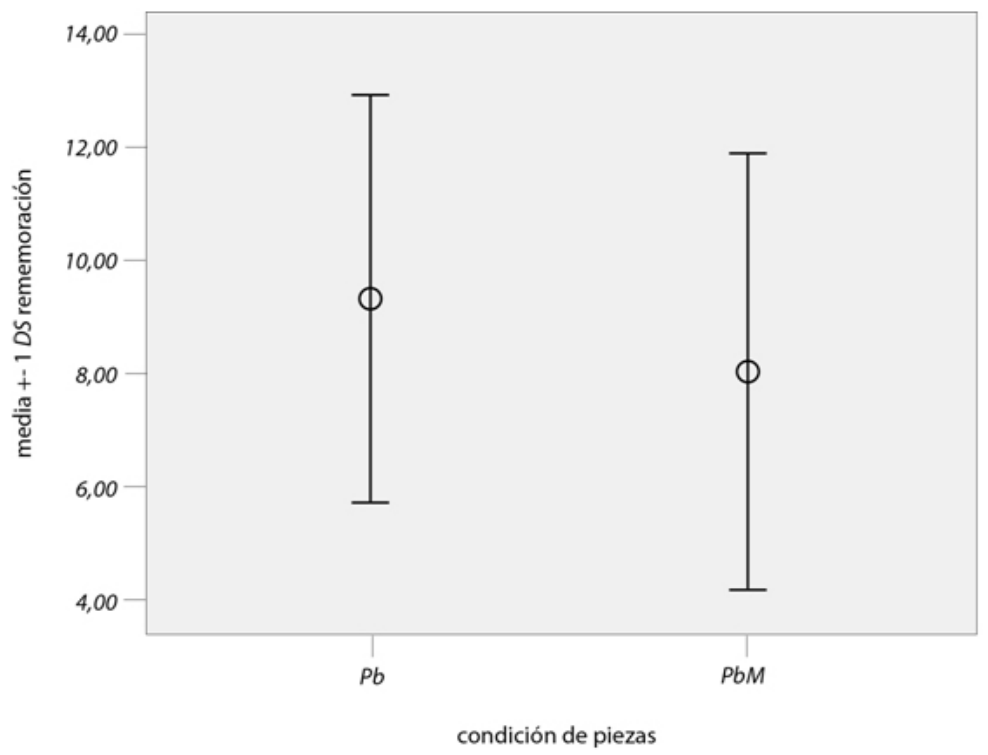

Figura 2. Barras de error comparativas de la evocación de anuncios en las condiciones Pb y PbM.

En cuanto a las figuras retóricas utilizadas en las piezas que manifestaron tener un grado de recordación por encima de la media en cada condición, se observó lo siguiente (ver Tabla 4): 


\begin{tabular}{ccccccc}
$\begin{array}{c}\text { Tipo de figura } \\
\text { retórica }\end{array}$ & $\begin{array}{c}\mathrm{N}^{\mathrm{o}} \text { total } \\
\text { de figuras } \\
\text { retóricas } \\
\text { en Pb y } \\
\mathrm{PbM}\end{array}$ & $\begin{array}{c}\mathrm{N}^{\mathrm{o}} \text { de piezas } \\
\text { evocadas } \\
\text { por encima } \\
\text { de la media }\end{array}$ & $\begin{array}{c}\text { Figura } \\
\text { retórica } \\
\text { presente } \\
\text { en } \mathrm{Pb}\end{array}$ & $\begin{array}{c}\text { Figura } \\
\text { retórica } \\
\text { presente } \\
\text { en PbM }\end{array}$ & $\begin{array}{c}\mathrm{N}^{\mathrm{o}} \text { de } \\
\text { sujetos que } \\
\text { evocaron la } \\
\text { pieza }\end{array}$ & $\%$ \\
\hline Metáfora & 7 & 3 & 0 & 3 & 30 & 17,5 \\
\hline Hipérbole & 7 & 2 & 1 & 1 & 27 & 15,5 \\
\hline Analogía & 3 & 2 & 2 & 0 & 24 & 14 \\
\hline Comparación & 1 & 1 & 1 & 0 & 12 & 7 \\
\hline Hipálage & 2 & 1 & 1 & 0 & 11 & 6,4 \\
\hline
\end{tabular}

Tabla 4. Figuras retóricas y evocaciones por encima de la media en las condiciones Pb y PbM.

Las piezas rememoradas con puntuaciones por encima de la media en las condiciones $P b$ y $P b M$ se muestran a continuación (ver Tabla 5):

Tipo de figura Piezas $\mathrm{Pb}$ evocadas por encima Piezas $\mathrm{PbM}$ evocadas por encima de la retórica de la media con figuras retóricas media con figuras retóricas

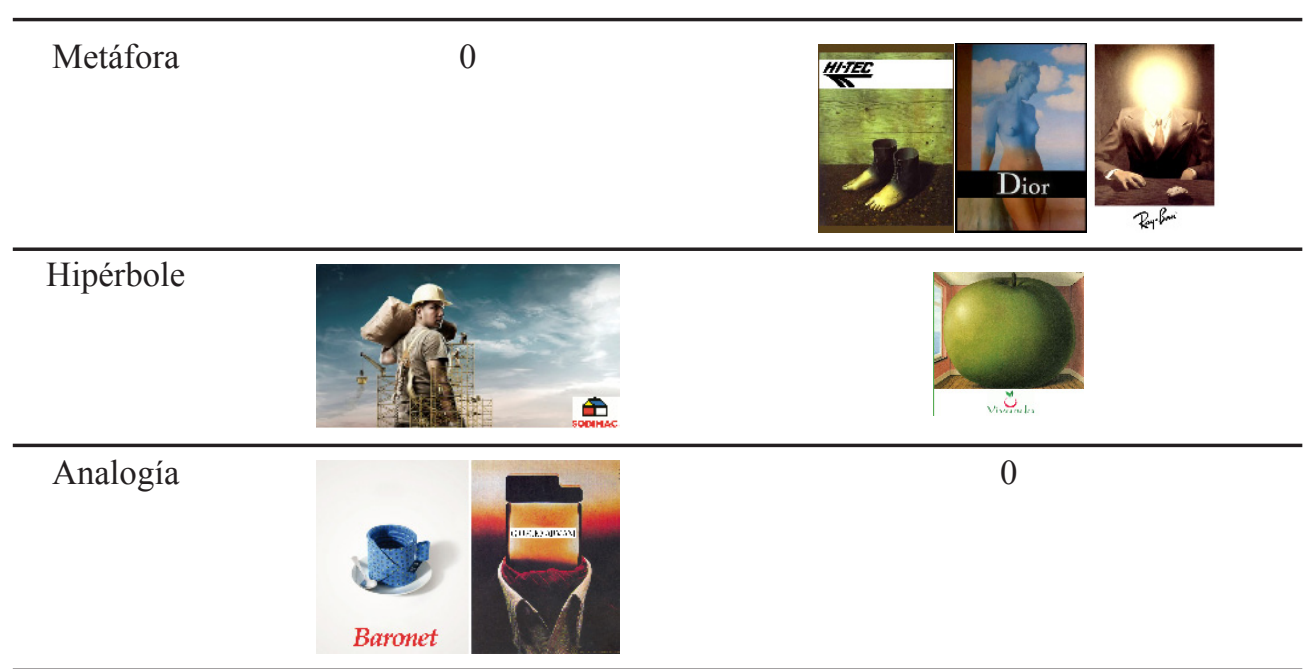

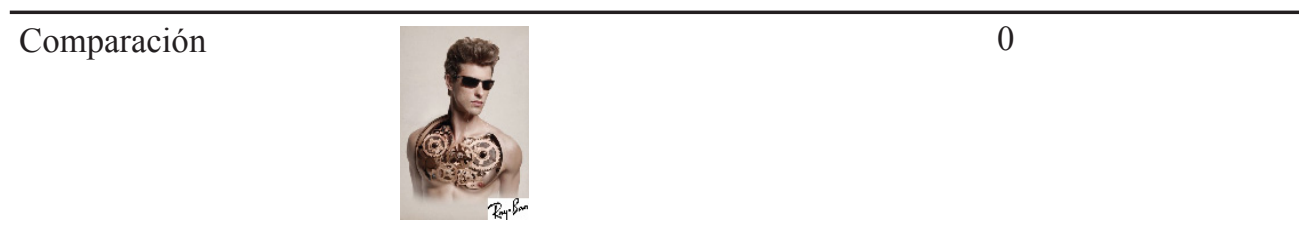

Comparación

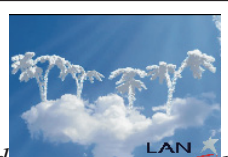

0

Tabla 5. Piezas rememoradas con punumuctones por encima de la media en las condiciones Pb y PbM. 
Finalmente, con el interés de observar la influencia de las piezas neutras $(P b S)$, es decir aquellas carentes de figuras retóricas y que fueron colocadas como elementos de contrabalanceo para controlar el efecto de primacía y recencia durante el experimento, también se utilizó una prueba de la $t$ de Student.

El resultado manifestó una marcada diferencia estadística en cuanto al recuerdo de las piezas experimentales $P b$ y $P b M$ en comparación con las piezas neutras $(P b S)$. El análisis reveló que los participantes recordaban con significativa diferencia éstas últimas, $t_{(22)}=-3.33, p<.003$, prueba bilateral.

media general de recordación también fue mayor en los anuncios neutros $(P b S)$ : 15.5 en comparación con 9.2 de $P b$ y 7.9 de $P b M$. La siguiente figura de barras de error ilustra la comparación entre los niveles de evocación entre ambas piezas experimentales y las neutras (ver Fig. 3).

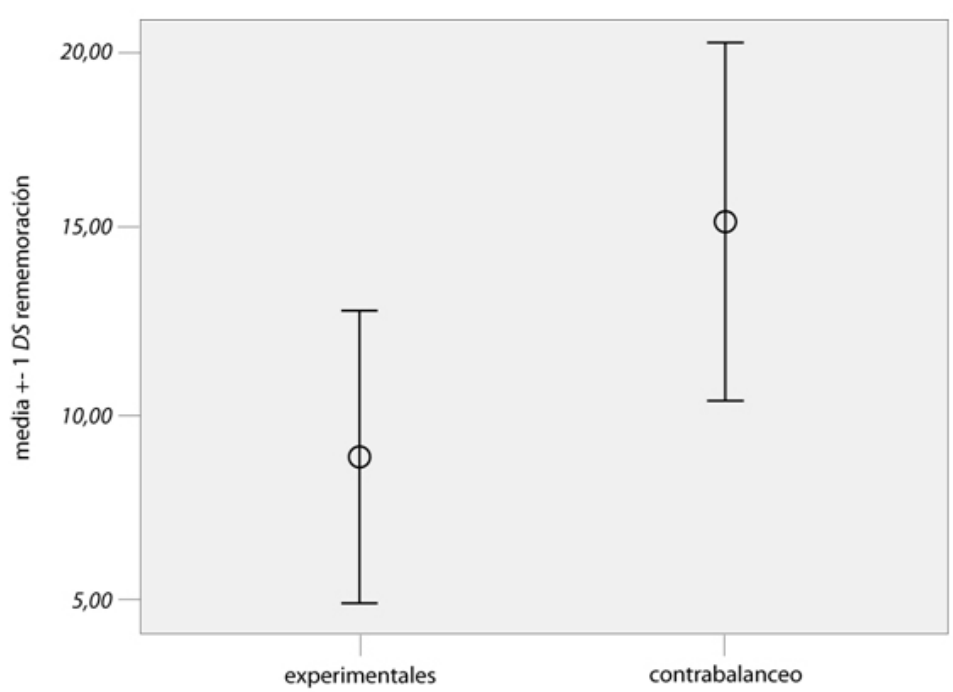

Figura 3. Barras de error de la evocación de anuncios en las condiciones experimentales (Pb y PbM) en comparación con la evocación con anuncios neutros (PbS).

\section{Conclusiones}

La hipótesis planteó que el uso de la figura retórica como parte del diseño funcional de una pieza publicitaria debía tener un mayor efecto que el retoricismo figurativo presente en las obras de Magritte, donde el recurso no se utiliza ni se encuentra presente con una finalidad operativa -generar conciencia o capturar la atención para originar recuerdos- sino como un elemento artístico al cual le corresponde por naturaleza la contemplación y agrado por parte del espectador.

Los resultados de esta investigación confirman esta tesis, mostrando que las piezas publicitarias que utilizan diversas figuras retóricas en su estructura narrativa sí logran un mayor índice de recordación en el corto plazo cuando se comparan con el 
arte magrittiano, donde las figuras se encuentran presentes por un motivo ajeno al comercial. De esta forma se puede afirmar que las piezas de comunicaciones de marketing diseñadas profesionalmente y que utilizan de modo premeditado las figuras retóricas como instrumentos visuales logran mejor su cometido.

Asimismo, no parece identificarse un único tipo de figura retórica visual que prime en cuanto a lograr mayores índices de recordación. Las tres figuras que los resultados del estudio identificaron causar más influjo fueron la metáfora, seguida por la hipérbole y luego, la analogía.

Al inicio del artículo se señaló que el esfuerzo mental requerido para la decodificación y reconocimiento de un estímulo conlleva a un mejor almacenamiento del mismo en la memoria. Es decir, que se observa una correspondencia proporcional entre la exigencia cognitiva que permite ver y comprender piezas compuestas con elementos complejos como las figuras retóricas y el posterior impacto en la memoria. O bien, expuesto de otro modo, se origina un mayor residuo en la memoria debido a la atención y elaboración sobre el anuncio. Esto también lo señalan autores como Lagerwerf, et al. (2012), entre otros.

Los resultados del presente estudio son congruentes con este fenómeno. Las piezas estrictamente publicitarias $(P b)$ contienen la complejidad de una figura retórica que exige decodificación por parte del espectador y, a su vez, este recurso se encuentra presente en ellas de modo premeditado y sujeto a una finalidad funcional, propia de las piezas de comunicaciones de marketing.

En contrapartida, si bien en las piezas magrittianas $(P b M)$ también contienen figuras retóricas, se advierte que su presencia no responde a un criterio funcional sino a uno artístico de naturaleza contemplativa. De ahí, es plausible concluir que si bien logran un efecto en la evocación al corto plazo, este no es tan alto como en el caso de la publicidad.

Por otro lado, se observó que las piezas publicitarias que no incluyeron estímulos complejos derivados de la utilización de figuras retóricas $(P b S)$ originaron unos niveles de recordación mayores que la publicidad y obras de arte de Magritte que sí lo hicieron, este suceso no fue esperado entre los resultados de la investigación. Es decir, no hubo expectativa de que el fenómeno de primacía y recencia tuviera un impacto tan alto como el reportado en este estudio.

\section{Prospectivas y limitaciones}

Como se ha señalado, las piezas neutras carentes de figuras retóricas, utilizadas como contrabalanceo en la experimentación, cobraron un al alto índice de recordación.

De esta manera cabe realizar futuras investigaciones para determinar si la figura retórica, como herramienta de narrativa visual, favorece la evocación pero sin ser necesariamente una variable determinante de este resultado.

Asimismo, parece conviene seguir estudiando si la primacía y recencia son un fenómeno más determinante en el proceso de estimulación visual y retención y evocación en el corto plazo, en comparación con la complejidad narrativa icónica provocada por el uso de figuras retóricas en las piezas publicitarias. 
Los resultados y conclusiones del estudio apuntan a la conveniencia de que la publicidad utilice elementos visuales que motiven el esfuerzo cognitivo por parte del consumidor. Esto puede deberse a la proporcionalidad entre el grado de relevancia en el procesamiento de información y el grado de retención de los estímulos -o datos- en la memoria de corto y largo plazo. De este modo, se sugiere oportuno que el diseño visual de las piezas publicitarias sea tal que requiera del individuo la atención, reflexión e imaginación para completar o comprender el mensaje.

Como todo estudio donde las condiciones y variables son controladas por parte del experimentador, existe el riesgo de disminuir la ecología, o similud con la realidad, del fenómeno analizado. Si bien esta investigación utilizó anuncios reales producidos por profesionales de la publicidad, así como auténticos cuadros de Magritte y logitpos de marcas reales, cabe identificar un aspecto del diseño experimental que no sucede como en la realidad. Se trata del orden de presentación y tipos de anuncios gráficos a los que las personas están expuestas. En este estudio se exhibieron sólo piezas publicitarias y magrittianas que contuviesen figuras retóricas en un orden consecutivo, así como piezas carentes de figuras retóricas al inicio y final de la colección antes mencionada. De este modo, es posible realizar investigaciones posteriores donde las piezas con figuras retóricas se exhiban en concomitancia con piezas carentes de las mismas y de forma aleatoria. La comparación y resultado de un estudio como el descrito enriquecería el cuerpo de conocimiento sobre estas figuras como recurso artístico y de composición publicitaria.

\section{Referencias}

Andrews, J. C., Durvasula, S. \&Akhter, S. H. (1990). A Framework for Conceptualizing and Measuring the Involvement Construct in Advertising Research. Journal of Advertising, 19 (4), 27-40.

Atkinson, R. C. \& Shiffrin, R. M. (1971). The Control of Short Term Memory. Scientific American, 225, 82-9.

Azizian, A. \& Polich, J. (2007). Evidence for Attentional Gradient in the Serial Position Memory Curve from Event-related Potentials. Journal Of Cognitive Neuroscience, 19 (12), 2071-2081.

Baddeley, A. D. (1986). Exploring the central executive. Quarterly Journal of Experimental Psychology, 49A, 5-28.

Barbara J. P. \& McQuarrie, E. F. (2004). Beyond Visual Metaphor: A New Typology of Visual Rhetoric. Advertising Marketing Theory, 4, 113-136.

Bathers, R. (1977). Image Music Text. New York: Hill and Wang.

Boozer, R. W., Wyld, D. \& Grant, J. (1991). Using metaphor to create more effective sales messages. Journal of Consumer Marketing, 8 (1), 59-67.

Bowers, J. W. \& Osborn, M. M. (1966). Attitudinal effects of selected types of concluding metaphors in persuasive speeches. Speech Monographs, 33 (2), 147-155.

Bulmer, S. \& Buchanan-Oliver, M. (2006). Visual rhetoric and global advertising imagery. Journal of Marketing Communications, 12 (1), 9-61. 
Calzada, M. (2011). Una aproximación empírica a la clasificación y traducción de las figuras retóricas en la publicidad. Babel, 57 (1), 32-57.

Cao, M. L. F. (1998). La retórica visual como análisis posible en la didáctica del arte y de la imagen. Arte, Individuo y Sociedad, 10, 39-64.

Corbett, E. (1971). Classical rhetoric for the modern student. New York: Oxford University.

Draguet, M. (2003). Magritte. Paris: Hazan.

Ellenbogen, R. \& Meiran, N. (2008). Working memory in vement in dual-task performance: Evidence from the backward compatibility effect. Memory and Cognition, 36 (5), 968-978.

Engle, R. W., Kane, M. J. \& Tuholski, S. W. (1999). Individual differences in working memory capacity and what they tell us about controlled attention, general fluid intelligence, and functions of the prefrontal cortex, 102-134; in Miyake, A. \& Shah, E. (eds.) Models of working memory: Mechanisms of active maintenance and executive control. New York: Cambridge University Press.

Eysenck, M. W. \& Keane, M. T. (2005). Cognitive Psychology: A Student's Handbook (5th Edition). New York: Psychology Press.

Forceville, C. (1994). Pictorial Metaphor in Advertisements. Metaphor and Symbolic Activity, 9 (1), 1-29.

Foucault, M. (2001). Esto no es una pipa. Barcelona: Anagrama.

Gablik, S. (2000). Magritte. London: Thames \& Hudson.

Goldenberg, J., Mazursky, D., Levav, A. \& Solomon, S. (2009). Cracking the ad code. Cambridge (London): Cambridge University Press.

Greenwald, A. G. \& Leavitt, C. (1984). An audience involvement in advertising: Four levels. Journal of Consumer Research, 11, 581-92.

Hagtvedt, H. \& Patrick, V. (2008). Art infusion: the influence of visual art on the perception and evaluation of consumer products. Journal of Marketing Research, 45 (3), 379-389.

Hernández, J.M. \& Madrid, S. (1999). Recursos retóricos de la publicidad española entre siglos. Revista de investigación lingüistica, 2 (2), 163-208.

Hetsroni, A. \& Tukachinsky, R. (2005). The use of fine art in advertising: a survey of creatives and content analysis of advertisements. Journal of Current Issues and Research in Advertising, 27 (1), 93-94.

Holyoak, K. J., \& Hummel, J. E. (2001). Toward an understanding of analogy within a biological symbol system. En Gentner, D., Holyoak, K. J. \& Kokinov, B. N. (Eds.), The analogical mind: Perspectives from cognitive science (161-195). Cambridge, MA: MIT Press.

Homer, P. M. \& Kahle, L. R. (1986). A social adaptation explanation of the effects of surrealism on advertising. Journal of Advertising, 15(2), 50-60.

Jeong, Se-Hoon (2008). Visual metaphor in advertising: is the persuasive effect attributable to visual argumentation or metaphorical rhetoric? Journal of Marketing Communications, 14(1), 59-73.

Jiménez, G. \& Gómez, D. (2006). El uso de la pintura en la publicidad de revistas femeninas en España. Análisis de la publicidad que usa pintura en la revista Vogue. Trípodos, 245-265. 
Keyelaar, P. E. \& Van Gisbergen, M. S. (2006). Openness in advertising. Occurrence and effects of open advertisements in magazines (Ph.D thesis Radboud University, Nijmegen), Wijchen: Drukkers, B.

Leigh, J. (1994). The use of figures of rhetoric in print ad headlines. Journal of Advertising, 23(2), 17-34.

Levy, E. K., Levy, D. E. \& Goldberg, M. E. (2004). Art and the Brain: The Influence of Art on Roger Shepard's Studies of Mental Rotation. Journal of the History of the Neurosciences: Basic and Clinical Perspectives, 13(1), 79-90.

Lugrin, G. (2002). La symbiose séculaire de l'art et de la publicité: Magritte dans tous ses états. ComAnalysis, (July), 1-10.

Luuk, L., van Hooijdonk, C. M. J. \& Korenberg, A. (2012). Processing visual rhetoric in advertisements: Interpretations determined by verbal anchoring and visual structure. Journal of Pragmatics, 44, 1836-1852.

McQuarrie, E. F. \& Mick, D. G. (1992). On resonance: a critical pluralistic inquiry into advertising rhetoric. Journal of Consumer Research, 19(2), 180-197.

McQuarrie, E. F. \& Mick, D. G. (1993). Reflections on classical rhetoric and the incidence of figures of speech in contemporary magazines advertisements. Advances in Consumer Research, 22, 424-37.

McQuarrie, E. F. \& Mick, D. G. (1996). Figures of rhetoric in advertising language. Journal of Consumer Research, 22, 424-37.

McQuarrie, E. F. \& Mick, D. G. (1999). Visual rhetoric in advertising: text interpretative, experimental, and reader-response analyses. Journal of Consumer Research, 26 (1), $37-54$.

Mensa, M. \& Roca, D. (2006). Magritte: creativo publicitario, Trípodos, 293-302.

Mensa, M. (2005). Magritte, publicist \& artist. One and the same? Com Analysis, (February), 1-7.

Mensa, M. (2009). René Magritte: simbiosis entre arte y publicidad. Anàlisi. Quaderns de Comunicació y Cultura, 39, 35-49.

Messaris, P. (1997). Visual Persuasion: The Role of Images in Advertising. Thousand Oaks: Sage.

Meuris, J. (1997). René Magritte (1898-1967). Köln: Taschen.

Meyers-Levy, J. \& Malaviya, P. (1999). Consumers' processing of persuasive advertising. An integrative framework of persuasion theories. Journal of Marketing, 63, 45-60.

Meyers-Levy, J. \& Peracchio, L. (1992). Getting an angle in advertising: The effect of camera angle on product evaluations. Journal of Marketing Research, 29(4), 454461.

Mick, D. G. \& Buhl, C. (1992). A meaning-based model of advertising experiences. Journal of Consumer Research, 191(3), 317-338.

Mick, D. G. (1992). Levels of subjective comprehension in advertising processing and their relations to ad perceptions attitudes and memory. Journal of Consumer Research, 18(4), 411-424.

Mio, J. S. (1996). Metaphor, politics, and persuasion, in: Mio, J. S \& Katz, A.N. (Eds.), Metaphor: Implications and applications. Mahwah, NJ: Erlbaum, 127-146. 
Mitchell, A. A. (1981). The Dimensions of Advertising Involvement, en Advances in Consumer Research, 08, 25-30. Ed. Monroe, K. B.; Ann Abor: Association for Consumer Research.

Mostafa, M. (2005). An experimental investigation of the Egyptian consumenrs' attitudes towards surrealism in advertising. International Journal of Consumer Studies, 3 (May), 216-231.

Mothersbaugh, D. L.; Huhmann, B. A. \& Franke, G. R. (2002). Combinatory and separative effects of rhetorical figures in consumers' effort and focus in ad processing. Journal of Consumer Research, 28, 589-602.

Nairne, J. S. (2003). Sensory and Working Memory, New York: John Wiley \& Sons. In Healy, A. F. \& Proctor, R. W. (Eds.), Handbook Of Psychology, 4 15), Experimental Psychology.

Ollinger-Zinque, G. \& Leen, F. (1998). René Magritte (1898-1967). Paris: Flammarion.

Paquet, M. (1994). René Magritte 1898-1967. El pensamiento visible. Madrid: Taschen.

Pardun, C. J. (2009). Advertising and society : controversies and consequences. Chichester: Wiley-Blackwell.

Passeron, R. (1980). René Magritte. New York: Filipacchi.

Peracchio, L. \& Meyers-Levy, J. (1994). How ambiguous cropped objects in ad photos can affect product evaluations. Journal of Consumer Research, 21(1), 190-204.

Peracchio, L. \& Meyers-Levy, J. (1997). Evaluating persuasion-enhancing techniques from a resource-matching perspective. Journal of Consumer Research, 24(2), 178191.

Peracchio, L. \& Meyers-Levy, J. (2005). Using stylistic properties of ad pictures to communicate with consumers. Journal of Consumer Research, 32(1), 29-40.

Phillips, B. J. \& McQuarrie, E. F. (2002). The development change and transformation rethorical style in magazine advertisements 1954-1999. Journal of Advertising, 31(4), 1-13.

Phillips, B. J. (2000). The impact of verbal anchoring on consumer response to image ads. Journal of Advertising, 29 (1), 15-24.

Plassman, H.; Zöega, R. T. \& Milosavljevic, M. (2012). Branding the brain: a critical review and outlook. Journal of Consumer Psychology, 22 (1), 18-36.

Read, S. J., Cesa, I. L., Jones, D. K., Collins, N. L. (1990). When is the federal budget like a baby? Metaphor in political rhetoric. Metaphor and Symbolic Activity, 5 (3), 125-149.

Reinsch, N. L. Jr. (1973). Attitudinal effects of brief and extended similes and metaphors. (Tesis inédita de doctorado). University of Kansas.

Roca, D. \& Mensa, M. (2006). Magritte: creativo publicitario. Tripodos, 1-12.

Roca, D. \& Mensa, M. (2010). Magritte's art stylistic patterns in Spanich advertising: one magazine content analysis (1995-2005). Congreso Internacional European Advertising Academy (ICORIA).

Rodgers, S. \& Thorson, E. (2012). Advertising theory. New York: Routledge.

Rodríguez Kauth, A. (2001). La ruptura de la percepción visual en el arte pictórico: Magritte. Arte, Individuo y sociedad, 13, 69-82.

Roque, G. (1983). Ceci n'est pas un Magritte. Essai sur Magritte et la publicité. Paris: Flammarion. 
Rossiter, J. R., Langner, T. \& Ang, L. (2003). Visual creativity in advertising: a functional typology. Marketing Communications Issues, 1-3 December, 105-113.

Schwilden, T. (1998). Magritte, liure l'image. Brussels: Galerie Bortier.

Scott, L. M. (1994). Image in advertising: the need for a theory of visual rhetoric. Journal of Consumer Research, 21(2), 252-273.

Segler, T. (2001). PhD Research Proposal: Second Language Vocabulary Acquisition and Learning Strategies in ICALL environments. Disponible en http: //homepages. inf.ed.ac.uk/s9808690/newprop.pedf 30.4.2006.

Sopory, P. \& Dillard, J. P. (2002). The persuasive effects of metaphor: a meta-analysis. Human Communication Research, 28 (3), 382-419.

Styles, E. (2005). Attention, perception and memory. An integrated introduction. New York: Psychology Press.

Surprenant, A. \& Neath, I. (2009). Principles of memory. New York: Psychology Press.

Sylvester, D. (1997). René Magritte, Catalogue Raisonné. Brussels: Menil Foundation.

Torczyner, H. (1978). Magritte: signos e imágenes. Barcelona: Blume.

Turow, J. \& Mcallister M. (2009). The Advertising and Consumer Culture Reader. New York: Routledge.

Vakratsas, D. \& Ambler, T. (1999). How Advertising Works: What Do We Really Know? Journal of Marketing, 63(1), 26-43.

Vargas, L. (2003). Procesamiento de información y familiaridad de marca. Anàlisi, 30, 225-240.

Vargas, L. (2004). Publicidad en Mercados Saturados. Piura: Facultad de Comunicación, Universidad de Piura.

Vargas, L. (2005). Efectos mentales de la exposición a información de marca. Global Media Journal, 1(2), 1-6.

Van Mulken, M., Van Enschot, R. \& Hoeken, H. (2005). Levels of implicitness in magazine advertisements: an experimental study into the relationship between complexity and appreciation in magazine advertisements. Information Design Journal and Document Design, 13 (2), 155-164.

Zaichkowsky, J. L. (1994). The Personal Involvement Inventory: Reduction, Revision, and Application to Advertising. Journal of Advertising, 23(4), 59-70.

Zhang, J., Yang, X. \& Peracchio, L. (2009). The persuasiveness of stylistic properties: the moderating role of ideal-self vs. ought-self. Advances in Consumer Research, $36,715-735$. 